\title{
Maternal Immune Activation During the Third Trimester Is Associated with Neonatal Functional Connectivity of the Salience Network and Fetal to Toddler Behavior
}

\author{
Marisa N. Spann, ${ }^{1}$ Catherine Monk, ${ }^{1,2}$-Dustin Scheinost, ${ }^{3}$ and Bradley S. Peterson ${ }^{4,5}$ \\ ${ }^{1}$ Department of Psychiatry, College of Physicians and Surgeons, Columbia University, New York, New York 10032, ${ }^{2}$ New York State Psychiatric Institute, \\ New York, New York 10032, ${ }^{3}$ Radiology and Biomedical Imaging and in the Child Study Center, Yale University School of Medicine, New Haven, \\ Connecticut 06520, ${ }^{4}$ Institute for the Developing Mind, Children's Hospital Los Angeles, Los Angeles, California 90027, and ${ }^{5}$ Department of Psychiatry, \\ Keck School of Medicine, University of Southern California, Los Angeles, California 90033
}

Prenatal maternal immune activation (MIA) is associated with altered brain development and risk of psychiatric disorders in offspring. Translational human studies of MIA are few in number. Alterations of the salience network have been implicated in the pathogenesis of the same psychiatric disorders associated with MIA. If MIA is pathogenic, then associated abnormalities in the salience network should be detectable in neonates immediately after birth. We tested the hypothesis that third trimester MIA of adolescent women who are at risk for high stress and inflammation is associated with the strength of functional connectivity in the salience network of their neonate. Thirty-six women underwent blood draws to measure interleukin-6 (IL-6) and C-reactive protein (CRP) and electrocardiograms to measure fetal heart rate variability (FHRV) at 34-37 weeks gestation. Resting-state imaging data were acquired in the infants at $40-44$ weeks postmenstrual age (PMA). Functional connectivity was measured from seeds placed in the anterior cingulate cortex and insula. Measures of cognitive development were obtained at 14 months PMA using the Bayley Scales of Infant and Toddler Development-Third Edition (BSID-III). Both sexes were studied. Regions in which the strength of the salience network correlated with maternal IL-6 or CRP levels included the medial prefrontal cortex, temporoparietal junction, and basal ganglia. Maternal CRP level correlated inversely with FHRV acquired at the same gestational age. Maternal CRP and IL-6 levels correlated positively with measures of cognitive development on the BSID-III. These results suggest that MIA is associated with short- and long-term influences on offspring brain and behavior.

Key words: cognition; maternal C-reactive protein; maternal immune activation; maternal interleukin 6; neonatal functional connectivity; salience network

Significance Statement

Preclinical studies in rodents and nonhuman primates and epidemiological studies in humans suggest that maternal immune activation (MIA) alters the development of brain circuitry and associated behaviors, placing offspring at risk for psychiatric illness. Consistent with preclinical findings, we show that maternal third trimester interleukin- 6 and C-reactive protein levels are associated with neonatal functional connectivity and with both fetal and toddler behavior. MIA-related functional connectivity was localized to the salience, default mode, and frontoparietal networks, which have been implicated in the pathogenesis of psychiatric disorders. Our results suggest that MIA alters functional connectivity in the neonatal brain, that those alterations have consequences for cognition, and that these findings may provide pathogenetic links between preclinical and epidemiological studies associating MIA with psychiatric risk in offspring.

\section{Introduction}

The third trimester of pregnancy is a time of rapid maturation of brain architecture and functional neural circuits (Tau and Peter- son, 2010), making those circuits highly vulnerable to environmental insults (Thompson et al., 2009; Scheinost et al., 2017a).

The authors declare no competing financial interests.

We thank the women who participated in this study and our research assistants, Michelle Gilchrest, Alida Davis, Ashley Rainford, and Kirwan Walsh, for dedicated help with participant engagement and data collection.

Correspondence should be addressed to Dr. Bradley S. Peterson, Institute for the Developing Mind, Children's Hospital Los Angeles, 4650 Sunset Boulevard, MS\# 135, Los Angeles, CA 90027. E-mail: bpeterson@chla.usc.edu. DOI:10.1523/JNEUROSCI.2272-17.2018

Copyright $\odot 2018$ the authors $\quad 0270-6474 / 18 / 382877-10 \$ 15.00 / 0$ 
Increasingly, maternal immune activation (MIA) - activation of the innate and adaptive immune system after infection, stress, poor physical health, and inflammation-is a common and consequential environmental insult on the developing brain (Estes and McAllister, 2016).

The activated immune system releases several classes of proteins to stimulate an immune response. Two of the most frequently released proteins are as follows: interleukin (IL)-6, a proinflammatory cytokine, and C-reactive protein (CRP), an acute phase reactant (Hunter and Jones, 2015; Estes and McAllister, 2016). IL-6 and CRP are commonly studied in clinical and translational research of various physiological systems (Pepys and Hirschfield, 2003; Hunter and Jones, 2015). However, IL-6 and CRP are less often studied in the context of early brain development.

Numerous preclinical models have studied the neurodevelopmental consequences of MIA in offspring of pregnant rodents or nonhuman primates (Bilbo et al., 2008; Bland et al., 2010; Short et al., 2010; Goeden et al., 2016). MIA in those models alters development of a widespread and nonspecific set of brain regions that include the hippocampus, prefrontal cortex, midtemporal lobe, parietal lobe, insula, and cingulate cortex (Patterson, 2002; Bland et al., 2010; Short et al., 2010). Offspring behavioral disturbances associated with MIA are more specific and include increased behavioral reactivity (or disinhibition) and deficits in emotion regulation, attention, and memory (Bilbo et al., 2005, 2008; Patterson, 2009; Malkova et al., 2012). In humans, most of these behaviors are related to the salience network, a large-scale brain network anchored in the insula and dorsal anterior cingulate (dACC) (Bush et al., 2000; Seeley et al., 2007; Uddin, 2015). These brain regions are implicated in psychiatric disorders such as autism spectrum disorders (ASD) and attention-deficit/hyperactivity disorder (Uddin et al., 2013; Sidlauskaite et al., 2016). Together, these converging results suggest that the salience network is a good candidate for investigations of functional connectivity associated with MIA.

Although epidemiological studies have associated MIA with increased risk of psychiatric disorders, including schizophrenia and ASD (Carter, 2009; Brown, 2012), few human studies have assessed directly the association of MIA with altered brain maturation and related behaviors. One study reported associations of IL-8 concentrations with ventricular, entorhinal cortex, and posterior cingulate volumes in individuals with schizophrenia (Ellman et al., 2010). Two infant studies reported an association of MIA with smaller head circumference, an indirect index of brain maturation (Lo et al., 2002; Leviton et al., 2010).

The goal of our study was to assess the association of MIA indices (maternal IL-6 and CRP levels) during the third trimester in a pregnant adolescent sample of women with neonatal brain measures of functional connectivity within the salience network, a network that has been implicated in the pathogenesis of MIAassociated neuropsychiatric illnesses (Menon, 2011; Palaniyappan and Liddle, 2012). Pregnant adolescents are at high risk for psychosocial stress from low socioeconomic status, low social support, and poor nutrition, all of which can contribute to MIA (Darroch, 2001; Diz-Chaves et al., 2013). We also assessed the association of maternal IL-6 and CRP levels with fetal heart rate and heart rate variability, physiological indices of autonomic nervous system (ANS) development, and cognitive abilities of the infants at age 14 months. We hypothesized that third trimester maternal IL-6 and CRP levels would correlate significantly with functional connectivity measures from seeds placed in the insula and AACC of their newborn infants. We hypothesized that the strength of this connectivity would in turn associate with fetal ANS maturation and infant cognitive capacities. The novelty of this research precluded specific hypotheses about the direction of these effects.

\section{Materials and Methods}

Participants. Nulliparous pregnant adolescent women, aged 14-19 years, were recruited in the second trimester through the Departments of Obstetrics and Gynecology at Columbia University Medical Center (CUMC) and Weill Cornell Medical College and flyers posted in the CUMC vicinity as part of a longitudinal study examining adolescent pregnancy behaviors and infant outcomes. The pregnant women received routine prenatal care and had no major health problems at the time of recruitment. Participating mothers provided informed consent and the study procedures were approved by the Institutional Review Boards of the New York State Psychiatric Institute and of CUMC. Participants were excluded if they acknowledged use of recreational drugs, tobacco, alcohol, or medications with an effect on cardiovascular function or lacked fluency in English. Of the 72 infants who underwent MRI scanning, 36 had usable fMRI data, 34 of those infants had usable immune data, 18 of whom had usable fetal data, and 21 of whom were administered the Bayley Scales of Infant and Toddler DevelopmentThird Edition (BSID-III) at age 14 months.

Fetal data. At 34-37 weeks of gestation, the women underwent a fetal heart rate (FHR) assessment; participants were in a semirecumbent position for $20 \mathrm{~min}$ as FHR was acquired. Data were obtained using an MT 325 fetal actocardiograph (Toitu). The fetal actocardiograph detects FHR via a single transabdominal Doppler transducer and processes this signal through a series of filters. FHR data were collected from the output port of the MT 325 and digitized at $50 \mathrm{~Hz}$ using a 16 bit A/D card (National Instruments 16XE50). Data were analyzed offline using custom MATLAB programs (The MathWorks) developed for this project. Two fetal variables were of interest: mean FHR and SD of FHR, our index of FHRV. As a first step in preprocessing, FHR $<80$ beats per minute (bpm) or $>200$ bpm was linearly interpolated and then low-pass filtered at $3 \mathrm{~Hz}$ using a 16 point finite impulse response filter. Mean and SD of the resulting FHR were taken over noninterpolated values. Filtered FHR was further examined for artifact in the following way: times at which the absolute sampleto-sample $(20 \mathrm{~ms})$ change in FHR exceeded $5 \mathrm{bpm}$ were found and FHR was marked as artifact until it returned to within $5 \mathrm{bpm}$ of the previous value. The resultant gaps were linearly interpolated.

Immune markers. Also at 34-37 weeks gestation, pregnant adolescents underwent blood draws to determine maternal IL-6 and CRP levels during the third trimester. IL- 6 was measured using an enzymelinked immunosorbent assay (ELISA) by R\&D Systems. The normal range values are $0.435-9.96 \mathrm{pg} / \mathrm{ml}$. CRP was measured using the Cobras Integra 400 Plus (Roche Diagnostics) turbid metric. Normal range values are $<0.5 \mathrm{mg} / \mathrm{dL}$.

Toddler assessment. The BSID-III was administered by a bachelor's level research assistant trained and supervised by a doctoral level psychologist to assess the developmental functioning of cognitive, language, and motor skills at 14 months (Bayley, 2005). The cognitive scale measures sensorimotor integration, concept formation, attention, habituation, and memory. Given that our previous findings that local volumes of the dACC on neonatal MRI scans correlated significantly with the cognitive subscale of the BSID-III acquired subsequently at age 18 months (Spann et al., 2014) and that the capacities measured by the cognitive subscale are most consistent with those affected by MIA and most relevant to the salience network (Bilbo et al., 2005, 2008; Patterson, 2009; Malkova et al., 2012), we focused our correlation analyses of connectivity on the cognitive subscale of the BSID-III. Scaled (age-standardized) scores for cognitive abilities were used in correlation analyses. The scaled score is a transformation of the raw score to the average performance of a normative sample at a specified age.

Imaging procedures. Infants were scanned within the first weeks of postmenstrual life (mean $=42.0 ; \mathrm{SD}=1.9$ weeks gestational age). They were fed, swaddled, and acclimated to the scanning environment and scanner noise by listening to a tape recording of the scanner sounds 


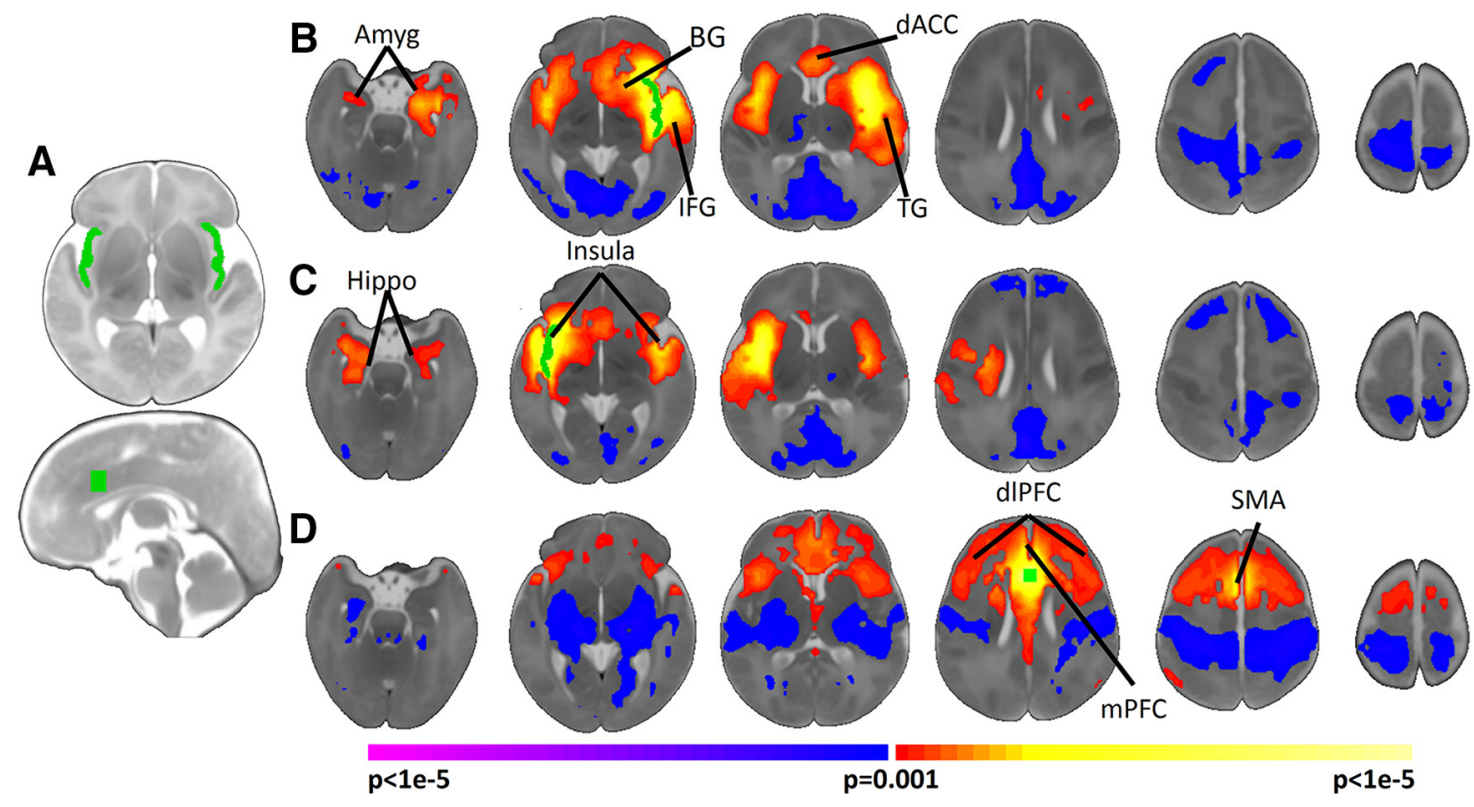

Figure 1. Neonatal salience network connectivity. $\boldsymbol{A}$, Regions of interest used for seed connectivity. The right and left insula and dACC seeds are shown in green. $\boldsymbol{B}, \boldsymbol{C}$, Left $(\boldsymbol{B})$ and right $(\boldsymbol{C})$ insula connectivity. The insula is functionally connected primarily to the contralateral insula, bilateral amygdala (Amyg), ipsilateral hippocampus (Hippo), ipsilateral basal ganglia (BG), ipsilateral IFG, ipsilateral temporal gyrus (TG), and the dACC. D, dACC connectivity. The dACC connectivity is functionally connected primarily to the dIPFC, mPFC, SMA, and bilateral anterior insula. Images are thresholded at $p<0.05$, corrected. Slices are shown in radiological convention.

played before each pulse sequence. The infants were given time to fall asleep without the use of sedatives, while lying on the scanner bed before the start of each sequence. Foam and wax ear plugs and ear shields (Natus Medical) were applied to dampen scanner noise. MRI-compatible EKG leads were placed on the infant's chest and a pulse oximetry sensor was placed on the infant's toe. Heart rate and oxygen saturation were monitored continually during the scan (InVivo Research).

Images were obtained using a 3 tesla General Electric Signa MRI scanner and an eight-channel head coil. Near the middle of the study's data collection, the MRI scanner was upgraded (see "Statistical analyses" section for analysis controlling for scanner type). High-resolution anatomical T2-weighted images were acquired using a 2D, multiple-shot, fast spin echo pulse sequence that used PROPELLER (Periodically Rotated Overlapping Parallel Lines with Enhanced Reconstruction) to reduce motion artifacts in reconstructed MR images (Pipe, 1999): repetition time $(\mathrm{TR})=10,000 \mathrm{~ms}$; echo time $(\mathrm{TE})=130 \mathrm{~ms}$; echo train length $(\mathrm{ETL})=32$; matrix size $=192 \times 192$; field of view $(\mathrm{FOV})=190 \times 190 \mathrm{~mm}$; phase $\mathrm{FOV}=100 \%$; slice thickness $=1.0 \mathrm{~mm}$; number of excitations $(\mathrm{NEX})=2$. The spatial resolution of the T2-weighted images was $1 \mathrm{~mm}^{3}$. Functional images were acquired using a standard echoplanar imaging sequence: $\mathrm{TR}=2200 \mathrm{~ms} ; \mathrm{TE}=30 \mathrm{~ms}$; matrix size $=64 \times 64 ; \mathrm{FOV}=190 \times$ $190 \mathrm{~mm}$; phase FOV $=100 \%$; slice thickness $=5.0 \mathrm{~mm}$, contiguous; number of slices $=24$; bandwidth $=7812.5 \mathrm{~Hz}$. Although the number of runs acquired varied per participant due to compliance, the median of 6 runs of 102 volumes ( 3 min $44.4 \mathrm{~s}$ each) were obtained for each infant.

Common space registration. First, anatomical images were skull stripped using FSL (https://fsl.fmrib.ox.ac.uk/fsl/) and any remaining nonbrain tissue was removed manually. All further analyses was performed using BioImage Suite (Joshi et al., 2011) unless otherwise specified. Anatomical images were linearly aligned to a single infant anatomical scan from an independent study (Scheinost et al., 2016) using a 12 parameter affine registration by maximizing the normalized mutual information between images. Next, anatomical images were nonlinearly registered to an evolving group average template in an iterative fashion using a previously validated algorithm (Scheinost et al., 2017b). This algorithm iterates between estimating a local transformation to align individual brains to a group average template and creating a new group average template based on the previous transformations. The local transformation was modeled using a free-form deformation parameterized by cubic B-splines. This transformation deforms an object by manipulating an underlying mesh of control points. The deformation for voxels in between control points was interpolated using B-splines to form a continuous deformation field. Positions of control points were optimized using a conjugate gradient descent to maximize the normalized mutual information between the template and individual brains. After each iteration, the quality of the local transformation was improved by increasing the number of control points and decreasing the spacing between control points to capture a more precise alignment. A total of 5 iterations were performed with decreasing control point spacings of $15 \mathrm{~mm}, 10 \mathrm{~mm}, 5 \mathrm{~mm}, 2.5 \mathrm{~mm}$, and $1.25 \mathrm{~mm}$. To help prevent local minimums during optimization, a multiresolution approach was used with three resolution levels at each iteration. Finally, functional images were rigidly aligned to the anatomical images.

All transformation pairs were calculated independently and combined into a single transform, warping the single participant results into common space. This single transformation allows the individual participant images to be transformed to the common space with only one transformation, thereby reducing interpolation error.

Connectivity processing. Motion correction was performed using SPM8 (http://www.fil.ion.ucl.ac.uk/spm/). Images were warped into $3 \mathrm{~mm}^{3}$ common space using the nonlinear transformation described above and cubic interpolation. Next, images were iteratively smoothed until the smoothness of any image had a full-width half maximum of $\sim 8 \mathrm{~mm}$ (Scheinost et al., 2014) using AFNI's 3dBlurToFWHM (http://afni.nimh. nih.gov/afni/). This iterative smoothing reduces motion-related confounds. Several covariates of no interest were regressed from the data, including linear and quadratic drifts, mean CSF signal, mean white matter signal, and mean gray matter signal. For additional control of possible motion-related confounds, a 24-parameter motion model (including six rigid-body motion parameters, six temporal derivatives, and these terms squared) was regressed from the data. The functional data were temporally smoothed with a Gaussian filter (approximate cutoff frequency $=$ $0.12 \mathrm{~Hz}$ ). A gray matter mask was applied to the data, so only voxels in the gray matter were used in further calculations.

Seed connectivity. Overall, there is paucity of previous literature investigating the effects of MIA on brain properties in humans across any age. Although the field of neuroinflammation is growing rapidly, neuroinflammation in adults can come from many different sources (e.g., disease, trauma, medication, illicit drug use), most of which are unrelated to the prenatal environment. In contrast, only one study to our knowledge has investigated MIA and later MRI (default mode network, DMN) measures of the brain (Ellman et al., 2010) and it reports an association only 
in individuals with schizophrenia, not in healthy controls. Because we do not know if any of our neonates will eventually develop schizophrenia, this prior study does not provide direct evidence of DMN associations with MIA in a normal population. Perhaps more relevant is the fact that the DMN is not readily detected in infants, especially when using the posterior cingulate cortex (PCC) as a seed (Smyser et al., 2010; Fransson et al., 2011), whereas the salience network is better formed in neonates (Smyser et al., 2010; Fransson et al., 2011; Alcauter et al., 2015). Moreover, animal studies of MIA consistently report alteration in the ACC and insula, as well as altered inhibition, emotional regulation, and attention to salience features (Patterson, 2002; Bilbo et al., 2005; Patterson, 2009; Bland et al., 2010; Short et al., 2010; Malkova et al., 2012). Together, these considerations provide compelling rationale to study dysregulation of the salience network in association with MIA.

We assessed whole-brain seed connectivity from the three primary nodes of the salience network (the dACC and left and right insula; Fig. 1). Seeds were defined on the reference brain and transformed back (via the inverse of the transforms described below) into individual participant space. The time course of the reference region in a given participant was then computed as the average time course across all voxels in the reference region. This time course was correlated with the time course for every other voxel in gray matter to create a map of $r$-values reflecting seed-to-whole-brain connectivity. These $r$-values were transformed to $z$-values using Fisher's transform, yielding one map for each seed and representing the strength of correlation with the seed for each participant.

Motion analysis. Given the technical challenges of scanning neonates, every participant had a different number of resting-state runs. For example, runs were stopped if the infant awoke, moved significantly, or cried during the run. Because motion and amount of data for analysis affects functional connectivity measures (Van Dijk et al., 2012; Noble et al., 2017), we used a strict inclusion criterion that participants had at least 2 runs of data with an average frame-to-frame motion of $<0.1 \mathrm{~mm}$. For the 36 participants with usable imaging data, the median number of partial or full runs collected per participant was 6 , with a range of 2-12 runs. The median number of runs removed was 2 , with a range of $0-8$ runs, leaving a median of 3 low motion runs per participant with a range of 2-7 runs. Therefore, we required a minimum of 2 low motion runs to retain the maximum number of participants while still having $>5$ min of restingstate data available from each infant for analysis. For infants with $>2$ runs with acceptable movement, we selected the 2 runs with the least frame-to-frame motion. We detected no significant correlations of motion indices with MIA measures (IL-6, $r=0.21, p=0.23$, df $=32$; CRP, $r=-0.19, p=0.39$; $\mathrm{df}=21$ ).

Further, as described above, we used global signal regression, regression of a 24-parameter motion model, and uniform smoothing to minimize motion confounds not accounted for by our inclusion criteria. Finally, given our strict motion inclusion criteria of an average frame-toframe displacement of $<0.1 \mathrm{~mm}$, only an average of 2.1 frames per participant had motion greater than the recommended censoring threshold of $0.2 \mathrm{~mm}$. Finally, to verify that these few high motion frames did not drive our results, we performed post hoc analysis using data censored at $0.2 \mathrm{~mm}$. This analysis did not change our results.

Experimental design and statistical analyses. Demographic and behavioral data were analyzed using either standard $\chi^{2}$ test statistics or Fisher's exact test for categorical data. Continuous-valued data were analyzed using either $t$ tests or Mann-Whitney $U$ tests when a normal distribution could not be assumed to compare groups. One-sample KolmogorovSmirnov and Lilliefors tests were used to confirm that IL- 6 and CRP values were normally distributed. All analyses were performed using SPSS 23 (IBM); $p$-values $<0.05$ were considered statistically significant.

Imaging data were analyzed using voxelwise linear models controlling for sex, postmenstrual age, and scanner upgrade, with all three covariates included in a single model. Significance was assessed at $p<0.05$, with all maps corrected for multiple statistical comparisons across gray matter using cluster-level correction estimated via AFNI's 3dClustSim (version 16.3.05) with 10,000 iterations, an initial cluster forming threshold of $p=$ 0.001 , the gray matter mask applied in preprocessing, and a mixed-model spatial autocorrelation function (ACF). Parameters for the spatial ACF were estimated from the residuals of the voxelwise linear models using
Table 1. Maternal demographics

\begin{tabular}{|c|c|}
\hline Variables & $n(\%)$ \\
\hline Age at delivery, $y^{a}$ & $17.6 \pm 3.4$ \\
\hline Pre-pregnancy body mass index ${ }^{a}$ & $25.1 \pm 6.8$ \\
\hline \multicolumn{2}{|l|}{ Years of education } \\
\hline $9^{\text {th }}$ grade & $3(8.3)$ \\
\hline $10^{\text {th }}$ grade & $7(19.4)$ \\
\hline $11^{\text {th }}$ grade & $9(25.0)$ \\
\hline $12^{\text {th }}$ grade or higher & $17(47.2)$ \\
\hline \multicolumn{2}{|l|}{ Race } \\
\hline Not Hispanic/Latino & $4(11.1)$ \\
\hline Hispanic/Latino & $32(88.9)$ \\
\hline \multicolumn{2}{|l|}{ Type of delivery } \\
\hline Vaginal spontaneous & $14(38.9)$ \\
\hline Assisted vaginal $^{b}$ & $10(27.8)$ \\
\hline Emergent Cesarean section ${ }^{c}$ & $8(22.2)$ \\
\hline \multicolumn{2}{|l|}{ Pregnancy complications ${ }^{d}$} \\
\hline None & $29(80.6)$ \\
\hline Complications & $4(11.1)$ \\
\hline
\end{tabular}

All mothers of Hispanic ethnicity were coded together.

${ }^{a}$ Data presented as mean \pm SD.

${ }^{b}$ Assisted vaginal includes induction and augmentation.

'Emergent Cesarean sections were due to arrest of dilatation/descent $(n=6)$, breech presentation $(n=1)$, and unknown reason $(n=1)$.

${ }^{d}$ Complications occurred across delivery types: vaginal spontaneous ( $\left.n=1\right)$ due to chorioamnionitis, assisted vaginal $(n=1)$ due to group B streptococcus, and emergent cesarean section $(n=2)$ due to acute nephritic syndrome and chorioamnionitis.

\section{Table 2. Neonatal demographics}

\begin{tabular}{lc}
\hline Variables & Mean \pm SD \\
\hline Gestational age at birth, wk & $39.4 \pm 1.3$ \\
Birth weight, g & $3199.4 \pm 436.9$ \\
Birth head circumference, cm & $34.1 \pm 1.3$ \\
Birth length, cm & $51.1 \pm 2.1$ \\
Apgar 1 min & $8.6 \pm 0.9$ \\
Apgar 5 min & $9.0 \pm 0.2$ \\
Postmenstrual age at scan, wk & $42.5 \pm 1.7$ \\
Gender, $n$ (\%) & \\
$\quad$ Male & $24(66.7)$ \\
$\quad$ Female & $12(33.4)$ \\
\hline
\end{tabular}

3dFWHMx. Exploratory and post hoc analyses were performed on average connectivity values extracted from regions of interest based on the initial analysis.

\section{Results}

\section{Demographic characteristics}

Maternal and neonatal demographic characteristics are summarized in Tables 1 and 2. The average age of the pregnant women was 17 years. The majority was still attending high school and a large proportion was Hispanic (89\%). The majority of infants were delivered vaginally $(67 \%)$. All infants were the appropriate size for gestational age (birthweight: $\mathrm{M}=3199.4, \mathrm{SD}=436.9 \mathrm{~g}$, gestational age at birth: $\mathrm{M}=39.4, \mathrm{SD}=1.3$ weeks) and were scanned at an average of $42.5(\mathrm{SD}=1.7)$ weeks postmenstrual age (PMA). The majority of infants were male (66.7\%).

Type of delivery was associated significantly with IL-6 level: pregnant women who had a C-section had the highest IL-6 levels $(\mathrm{M}=2.10, \mathrm{SD}=0.64 \mathrm{pg} / \mathrm{ml})$, pregnant women who had a spontaneous vaginal delivery had moderate IL-6 levels $(\mathrm{M}=1.76, \mathrm{SD}=$ $0.92 \mathrm{pg} / \mathrm{ml}$ ), and pregnant women who had an assisted vaginal delivery had the lowest IL-6 levels $(\mathrm{M}=1.19, \mathrm{SD}=0.39 \mathrm{pg} / \mathrm{ml})$. No other significant correlations were found between the immune markers and the demographic variables. Furthermore, demographic variables did not differ significantly in infants who had compared 


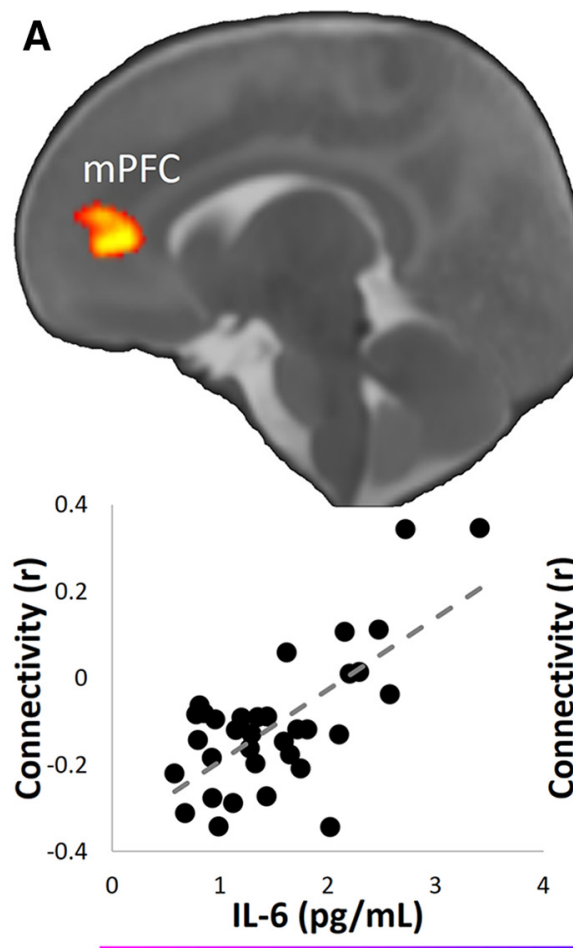

$\mathrm{p}<1 \mathrm{e}-5$

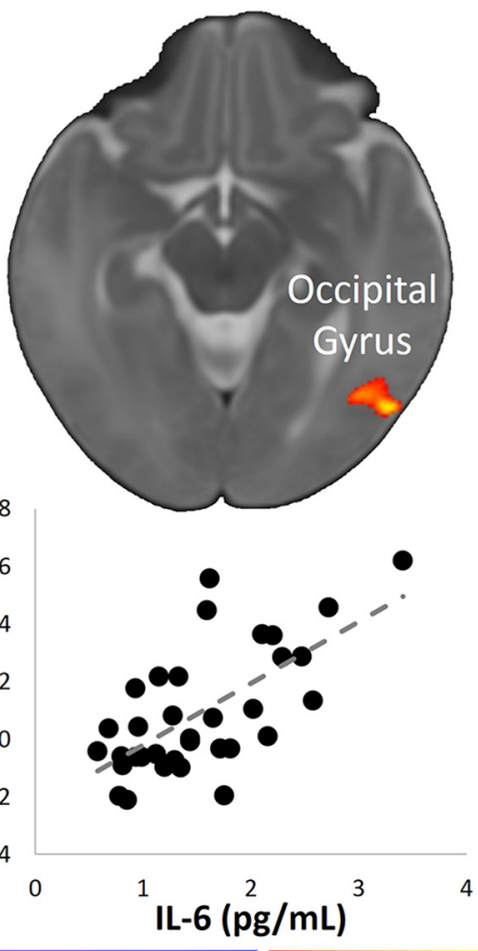

$p=0.001$

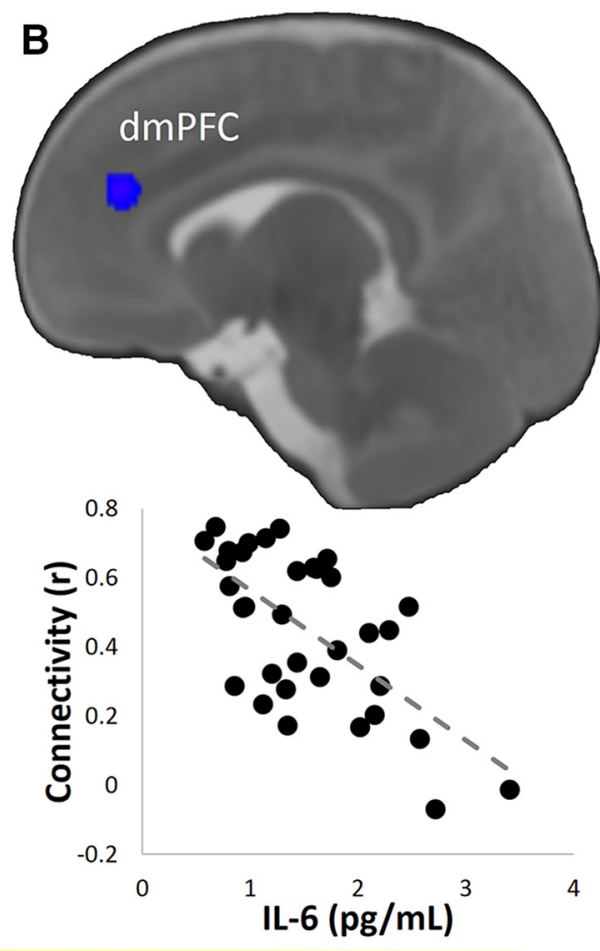

$p<1 e-5$

Figure 2. Association of maternal IL-6 levels and connectivity in the infant salience network. $\boldsymbol{A}$, Left insula seed. Higher levels of maternal IL-6 were associated with greater infant connectivity of the left insula with mPFC and left lateral occipital gyrus. B, dACC seed. Higher levels of maternal IL- 6 were associated with weaker infant connectivity of the dACC with dmPFC. Images are thresholded at $p<0.05$, corrected. Slices are shown in radiological convention. Scatterplots below the images visualize the distribution of the observed data points for average infant connectivity in the significant regions plotted against maternal IL-6 concentrations.

with those who did not have neonatal (usable MRI) data $(p>0.05)$, or when comparing infants with and without 14-month (BSID-III) follow-up cognitive measures ( $p>0.05)$.

On average, IL-6 values were within normal limits of nonpregnant individuals, with a mean of $1.7(\mathrm{SD}=1.0)$ and ranging from $0.58-5.58 \mathrm{pg} / \mathrm{ml}$. CRP values on average were higher than normative values of nonpregnant individuals, with a mean of 5.9 $(\mathrm{SD}=3.1)$ and ranging from 1 to $15 \mathrm{mg} / \mathrm{dL}$. The correlation between IL-6 and CRP was not significant $(r=0.39, p=0.08$, $\mathrm{df}=19)$.

\section{Salience connectivity in neonates}

Activity in the left insula correlated significantly $(p<0.05$, corrected) with local activity in left hemisphere regions (including the amygdala, hippocampus, basal ganglia, temporal gyri, and inferior frontal gyrus), the right insula and amygdala, and dACC (Fig. $1 B$ ). Significant ( $p<0.05$, corrected) negative connectivity with the left insula was observed for the PCC, visual cortex, bilateral motor cortex, and right dorsal lateral prefrontal cortex (dlPFC).

Similar to findings for the left insula, the right insula was significantly ( $p<0.05$, corrected) connected to local right hemisphere circuitry (including the amygdala, hippocampus, basal ganglia, temporal gyri, and inferior frontal gryus), the left insula, amygdala, and hippocampus (Fig. 1C). Significant inverse correlation of right insula activity was observed with the PCC, visual cortex, left motor cortex, and bilateral dlPFC.

The dACC was significantly connected to bilateral dlPFC, supplementary motor area, medial prefrontal cortex (mPFC), and bilateral insula (Fig. 1D). Significant negative connectivity with the dACC was observed for subcortical regions, auditory cortex, and bilateral motor cortex.

\section{Associations of maternal IL-6 levels with salience network connectivity}

Higher maternal IL-6 levels associated with greater connectivity between the left insula and MPFC and between the left insula and left lateral occipital gyrus (Fig. 2A); higher IL-6 levels were associated with weaker connectivity between the dACC and dorsomedial PFC (dmPFC; Fig. 2B). No significant correlations between maternal IL-6 and right insula connectivity were observed. Post hoc partial correlation using the average connectivity values extracted from regions of interest based on the initial analysis was performed with the main findings of IL- 6 controlling for type of delivery because of the significant correlation between IL-6 and type of delivery. The significant findings remained unchanged. Because two potential outliers were observed in the left insulamPFC connectivity values, we repeated the analyses removing those participants. The findings remained significant. Finally, similar $r$ - and $p$-values were observed when using Spearman's correlation instead of Pearson's correlation.

\section{Associations of maternal CRP levels with salience} network connectivity

The associations of maternal CRP levels with connectivity measures in the infant salience network were similar to the associations for IL-6 even though maternal CRP and IL-6 levels were not significantly correlated with one another. Higher maternal CRP levels were associated with greater infant connectivity between the left insula and right temporoparietal junction (Fig. 3A); 
greater connectivity between the right insula and basal ganglia (Fig. 3B) and between the dACC and the cuneus, temporoparietal junction, and extrastriate cortex (Figs. 3B, 4); and weaker connectivity between the dACC and $\mathrm{dmPFC}$ and right basal ganglia (Fig. 4). Finally, similar $r$-and $p$-values were observed when using Spearman's correlation instead of Pearson's correlation.

\section{Associations of MIA and neonatal connectivity with fetal heart rate measures}

Higher maternal CRP levels associated with lower FHRV $(r=-0.56, p=0.02$, $\mathrm{df}=16)$. No significant correlation with fetal heart rate or salience network measures was demonstrated. There was no significant finding for IL- 6 and fetal indices. Higher FHRV was associated with greater infant connectivity between the $\mathrm{dACC}$ and $\mathrm{mPFC}(r=0.58, p=0.01, \mathrm{df}=$ 15). Post hoc analyses assessing whether infant connectivity between the dACC and $\mathrm{mPFC}$ mediated the association of maternal CRP with FHRV were not statistically significant.

\section{Associations of MIA and neonatal connectivity with toddler behavior} Higher maternal IL-6 and CRP levels associated with higher cognitive scores on the BSID-III at 14 months postnatal age (IL-6, $r=0.69, p=0.002, \mathrm{df}=16$; CRP, $r=0.53, p=0.05, \mathrm{df}=$ 14). Greater infant connectivity between the dACC and mPFC associated with lower cognitive scores on the BSID-III $(r=$ $-0.60, p=0.02, \mathrm{df}=18)$. Post hoc analyses assessing whether connectivity between the dACC and MPFC mediated the association of MIA (either IL-6 or CRP) with cognitive scores were not statistically significant.

\section{Discussion}

In this prospective study, third trimester MIA was associated with measures of the fetal ANS, infant brain functional connectivity, and toddler cognitive outcomes. We measured IL- 6 and CRP levels in maternal blood at 34-37 weeks gestation as indices of MIA. We measured fetal heart rate and variability concurrent with MIA measures, functional connectivity in the salience network in infants at $40-44$ weeks PMA, and BSID-III cognitive scores at 14 months. Third trimester MIA indices (IL- 6 and CRP levels) correlated significantly with the strength of connectivity in the salience network in the mPFC, temporoparietal junction, and basal ganglia. Maternal CRP levels correlated inversely with FHRV. Maternal CRP and IL-6 levels each correlated positively with BSID-III cognitive scores at age 14 months. Finally, connectivity between the AACC and mPFC correlated with both FHRV and cognitive scores. Together, these findings suggest that third trimester MIA influences both short- and long-term features of human nervous system development at birth and in the toddler years, respectively.

Our most consistent observations were that MIA indices correlated with the strength of the salience network in the MPFC and temporoparietal junction. The $\mathrm{mPFC}$ is a major node in the DMN, whereas the temporoparietal junction is a major node in the frontoparietal network (Power et al., 2011; Yeo et al., 2011). Interactions between the salience network, $\mathrm{DMN}$, and frontoparietal network have been related to the competition between internally and externally directed attention (Uddin, 2015). In this model, the DMN attends to internal stimuli, the frontoparietal network attends to external stimuli, and the salience network acts as a switch between the two (Seeley et al., 2007; Uddin, 2015). Altered interactions between these networks are thought to play a role in the pathogenesis of abnormal cognition and perception in several psychiatric disorders (Menon, 2011), consistent with findings from epidemiological studies reporting significant associations of maternal IL- 6 and CRP with an increased risk in offspring of developing schizophrenia and ASD (Wei et al., 2013; Canetta et al., 2014; Mansur et al., 2016). Although we chose to study the salience network, our results point to alterations in the DMN and frontoparietal networks as well. These networks can be considered in future research.

Although we did not detect a statistically significant mediation effect of neonatal connectivity on the association of MIA with offspring outcomes, one prior study in humans (Ellman et al., 2010) and several in animals (Bilbo et al., 2005; Ellman et al., 2010) suggest that MIA in utero likely affects fetal brain development, which in turn produces postnatal behavioral disturbances. Therefore, our findings of MIA-related alterations in functional connectivity in infants may provide a pathogenic link between MIA and the well documented, subsequent increased risk of psychiatric disorders in offspring. 


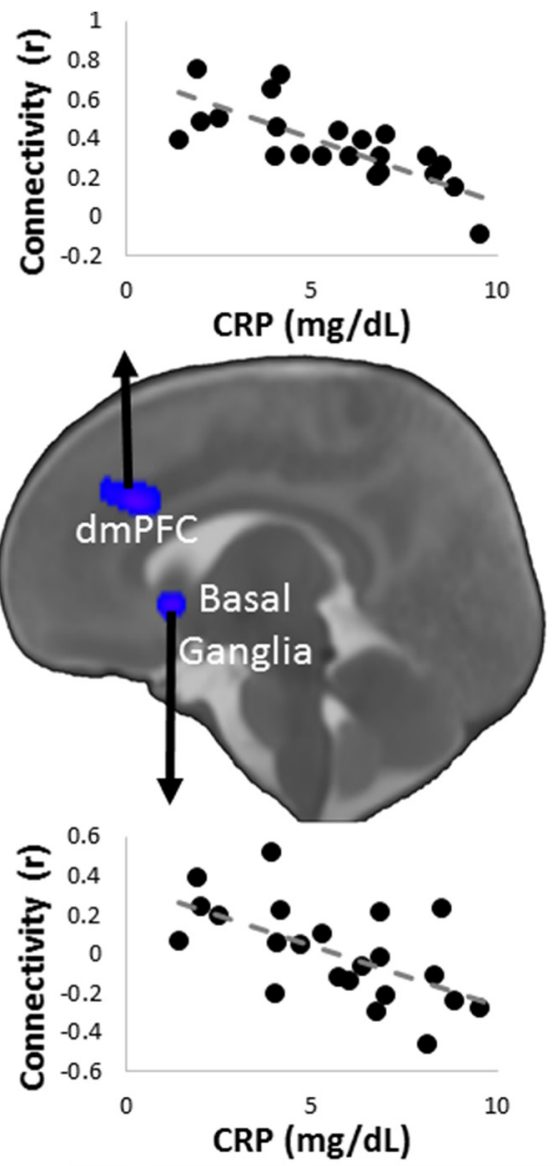

$p<1 e-5$
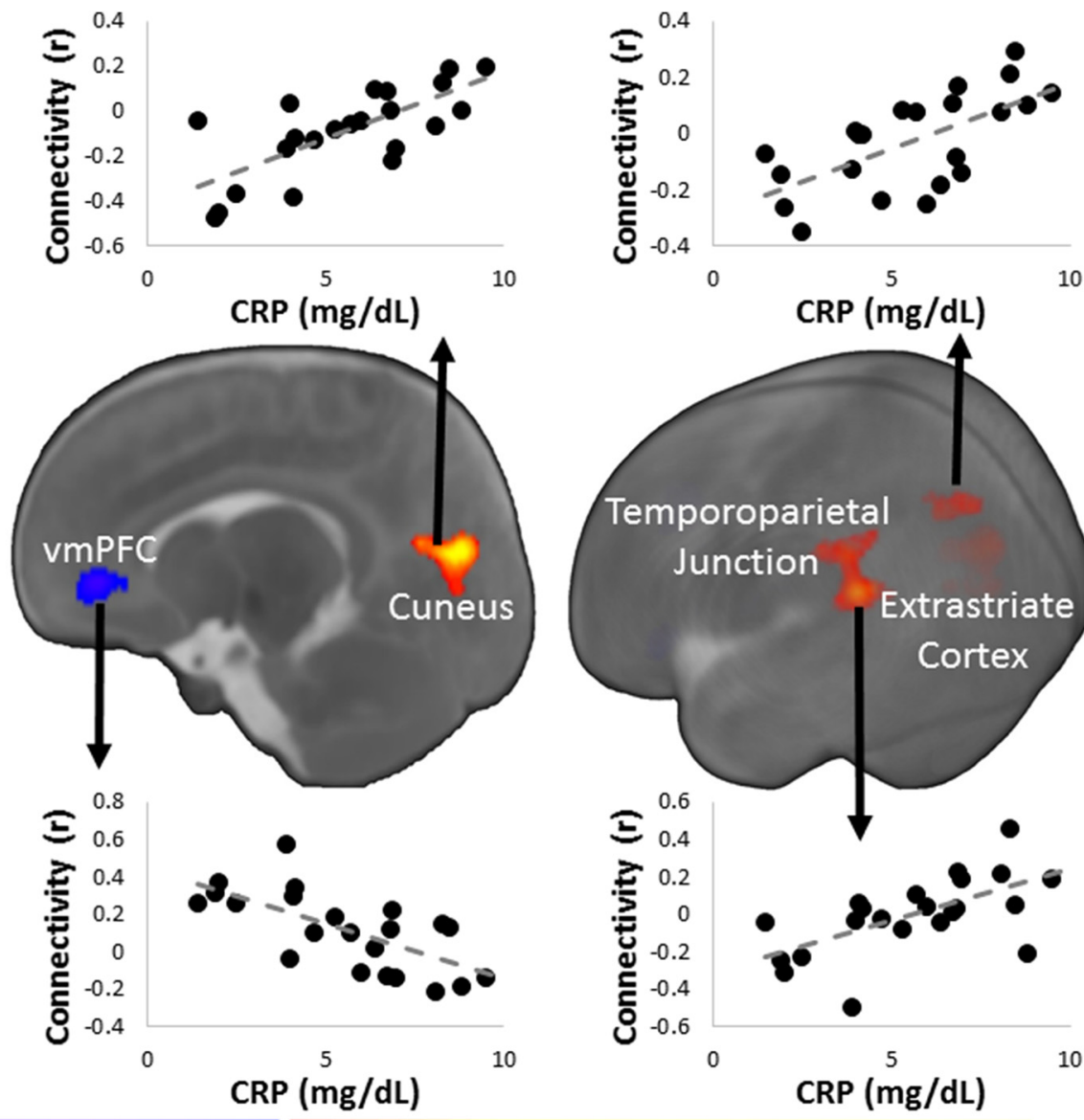

10

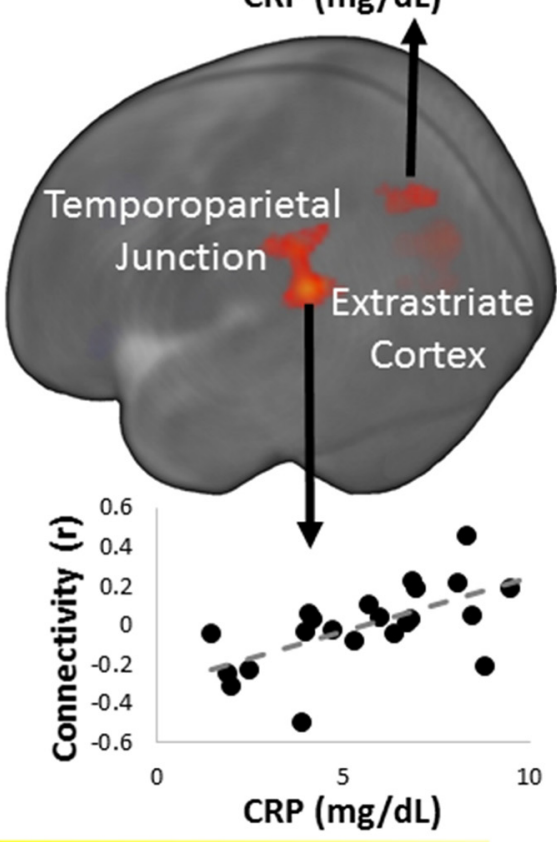

$p<1 e-5$

Figure 4. Association of maternal CRP levels and infant $d A C C$ connectivity. Higher levels of maternal CRP associated with weaker infant connectivity between the $d A C C$ and the dmPFC, vmPFC, and right basal ganglia, as well as with greater connectivity between the dACC and the cuneus, left temporoparietal junction, and left extrastriate cortex. Images are thresholded at $p<0.05$, corrected. Slices are shown in radiological convention. Scatterplots below the images visualize the distribution of the observed data points for average infant connectivity in the significant regions plotted against maternal CRP concentrations.

Preclinical studies suggest that IL-6 is key for MIA-associated alterations of the developing brain (Smith et al., 2007). For example, in a mouse model that overexpresses IL-6 in the brain, increasing IL-6 increased the number of excitatory synapses, decreased the number of inhibitory synapses, and altered the morphology of dendritic spines (Wei et al., 2012). IL-6 crosses both the placenta and blood-brain barrier (Banks et al., 1994; Zaretsky et al., 2004), suggesting that it can reach the fetal brain. Increasing maternally derived IL-6 in the human fetal brain could produce effects similar to those reported in these preclinical models. Alternatively, because IL-6 is part of both the pro-inflammatory and antiinflammatory pathways (Xing et al., 1998; Yasukawa et al., 2003), an imbalance of pro-inflammatory and anti-inflammatory signaling has been proposed as a mechanism responsible for MIA-related changes in offspring brain development (Meyer et al., 2008). The association of this imbalance with specific brain networks has yet to be established.

CRP signaling pathways may alter brain development in several different ways. Previous studies have shown that elevated CRP can produce vascular dysfunction and suboptimal placental development, which eventually interferes with fetal growth (Lam et al., 2005; Ernst et al., 2011). Because CRP also plays a role in normal synaptic pruning via the complement system (Stephan et al., 2012), altered maternal CRP levels may alter functioning of the complement system and thereby alter synaptic pruning in offspring (Canetta et al., 2014). Finally, elevated CRP levels may simply index poor general and mental health (Wium-Andersen et al., 2013; Shanahan et al., 2014), which can themselves alter brain development and behavioral outcomes in offspring (Chittleborough et al., 2012; O'Neil et al., 2014) and could therefore account for some of our observations.

Consistent with findings from preclinical studies (Bilbo et al., 2005; Patterson, 2009), we observed an association of MIA with concurrent FHRV, a maturational index for the ANS. Maternal CRP level correlated inversely with FHRV, which typically increases from the second to third trimester as the vagal nerve matures (DiPietro et al., 1996). Greater FHRV during this period is reported to predict later cognitive development at 2 and 2.5 years of age (DiPietro et al., 2007). Therefore, our findings suggest that MIA may slow fetal development of the ANS, possibly representing a vulnerability for long-term neurodevelopmental outcomes.

In contrast to these neurodevelopmental correlates concurrent with MIA measurement, we detected positive correlations of maternal CRP and IL-6 levels with subsequent BSID-III subsequent cognitive scores in the toddler years. The cognitive domain on the BSID-III assesses capacities that include attention, sensorimotor integration, and early executive functions and predicts 
future cognitive abilities at school age (Smith et al., 2001; Bayley, 2005; Spencer-Smith et al., 2015). The positive correlations between MIA measures and later cognitive outcomes, if replicated in future studies, could suggest that infants may mobilize an adaptive neurodevelopmental response to the presence of MIA. In support of this possibility, several preclinical studies have also reported adaptive or resilience responses associated with MIA. For example, neonatal bacterial infection in rats leads to a protection against induced depressive-like behaviors in adulthood (Bilbo et al., 2008). Therefore, both resilience and vulnerability may be associated with MIA, similar to the effects that other early life factors, including stress, have on neurodevelopmental outcomes (McEwen, 2007).

We observed strong connectivity in infants between the three nodes of the salience network, which is generally similar to connectivity patterns of the salience networks in children and adults (Seeley et al., 2007; Alcauter et al., 2015). That the salience network in infants is comparable in its organization to the network in older individuals is consistent with recent evidence in term and preterm infants that functional networks develop throughout the third trimester (Doria et al., 2010; Smyser et al., 2010; Jakab et al., 2014; Thomason et al., 2017).

Our study has several strengths. It acquired data prospectively beginning in the second trimester of pregnancy and continuing in the infants through 14 months. Two measures of MIA were collected, allowing assessment of their shared and unique effects on infant outcomes. Finally, MRIs were acquired in the infants soon after birth, allowing us to attribute functional characteristics largely to prenatal, rather than postnatal, factors.

Our study also has several limitations. Our maternal sample consisted of adolescents, who are at higher risk for prenatal distress. Therefore, the observed associations may not generalize to other populations. Although data were collected prospectively, our study lacks repeated measures of the same constructs across development. Developmental trajectories of functional connectivity may have provided a better assessment of the MIA-related influences on the developing brain (Di Martino et al., 2014). Maternal CRP levels were generally above the normal range, perhaps reflecting the young age and relatively high stress in our sample, although CRP is known to be slightly elevated during pregnancy (von Versen-Hoeynck et al., 2009). In addition, we observed significant pairwise correlations among MIA, infant connectivity, and toddler cognition, yet mediator analyses failed to confirm that neonatal functional connectivity mediated the association of MIA with toddler cognition. Our sample size likely limited our statistical power to detect mediation effects. Further, numerous factors can cause chronic or transient elevations in immune markers (Estes and McAllister, 2016). We were not able to account for all of these factors or differentiate between chronic and transient MIA. Future studies should investigate the diverse causes of MIA as different mechanisms that alter brain-behavior association likely exist. IL-6 can trigger the release of CRP (Gabay and Kushner, 1999), likely leading to shared variance between CRP and IL-6. Some of our CRP findings may represent downstream effects of IL-6 signaling (Karlović et al., 2012). Nevertheless, IL-6 and CRP were not correlated in our sample. CRP is involved in other signaling pathways, independent of IL-6 (Stephan et al., 2012). Therefore, our CRP findings likely reflect both unique and shared variance relative to our IL-6 findings.

Consistent with findings from preclinical studies, we showed that third trimester MIA likely influences the developing brain. Our findings provide evidence that MIA is associated with functional networks implicated in psychiatric disorders and animal models of those illnesses. Future human studies should acquire measures of inflammation, offspring functional connectivity, and additional immune proteins at multiple time points throughout development. They should also manipulate MIA levels experimentally, presumably in prevention trials, to demonstrate more definitively the causality of MIA on outcomes (Peterson, 2013).

\section{References}

Alcauter S, Lin W, Keith Smith J, Gilmore JH, Gao W (2015) Consistent anterior-posterior segregation of the insula during the first 2 years of life. Cereb Cortex 25:1176-1187. CrossRef Medline

Banks WA, Kastin AJ, Gutierrez EG (1994) Penetration of interleukin-6 across the murine blood-brain barrier. Neurosci Lett 179:53-56. CrossRef Medline

Bayley N (2005) Bayley Scales of Infant and Toddler Development, Ed 3: Administration manual. San Antonio, TX: Harcourt Assessment.

Bilbo SD, Biedenkapp JC, Der-Avakian A, Watkins LR, Rudy JW, Maier SF (2005) Neonatal infection-induced memory impairment after lipopolysaccharide in adulthood is prevented via caspase-1 inhibition. J Neurosci 25:8000-8009. CrossRef Medline

Bilbo SD, Yirmiya R, Amat J, Paul ED, Watkins LR, Maier SF (2008) Bacterial infection early in life protects against stressor-induced depressivelike symptoms in adult rats. Psychoneuroendocrinology 33:261-269. CrossRef Medline

Bland ST, Beckley JT, Young S, Tsang V, Watkins LR, Maier SF, Bilbo SD (2010) Enduring consequences of early-life infection on glial and neural cell genesis within cognitive regions of the brain. Brain Behav Immun 24:329-338. CrossRef Medline

Brown AS (2012) Epidemiologic studies of exposure to prenatal infection and risk of schizophrenia and autism. Dev Neurobiol 72:1272-1276. CrossRef Medline

Bush G, Luu P, Posner MI (2000) Cognitive and emotional influences in anterior cingulate cortex. Trends Cogn Sci 4:215-222. CrossRef Medline

Canetta S, Sourander A, Surcel HM, Hinkka-Yli-Salomäki S, Leiviskä J, Kellendonk C, McKeague IW, Brown AS (2014) Elevated maternal C-reactive protein and increased risk of schizophrenia in a national birth cohort. Am J Psychiatry 171:960-968. CrossRef Medline

Carter CJ (2009) Schizophrenia susceptibility genes directly implicated in the life cycles of pathogens: cytomegalovirus, influenza, herpes simplex, rubella, and toxoplasma gondii. Schizophr Bull 35:1163-1182. CrossRef Medline

Chittleborough CR, Lawlor DA, Lynch JW (2012) Prenatal prediction of poor maternal and offspring outcomes: implications for selection into intensive parent support programs. Matern Child Health J 16:909-920. CrossRef Medline

Darroch JE (2001) Adolescent pregnancy trends and demographics. Curr Womens Health Rep 1:102-110. Medline

Di Martino A, Fair DA, Kelly C, Satterthwaite TD, Castellanos FX, Thomason ME, Craddock RC, Luna B, Leventhal BL, Zuo XN, Milham MP (2014) Unraveling the miswired connectome: a developmental perspective. Neuron 83:1335-1353. CrossRef Medline

DiPietro JA, Hodgson DM, Costigan KA, Hilton SC, Johnson TR (1996) Fetal neurobehavioral development. Child Dev 67:2553-2567. CrossRef Medline

DiPietro JA, Bornstein MH, Hahn CS, Costigan K, Achy-Brou A (2007) Fetal heart rate and variability: stability and prediction to developmental outcomes in early childhood. Child Dev 78:1788-1798. CrossRef Medline

Diz-Chaves Y, Astiz M, Bellini MJ, Garcia-Segura LM (2013) Prenatal stress increases the expression of proinflammatory cytokines and exacerbates the inflammatory response to LPS in the hippocampal formation of adult male mice. Brain Behav Immun 28:196-206. CrossRef Medline

Doria V, Beckmann CF, Arichi T, Merchant N, Groppo M, Turkheimer FE, Counsell SJ, Murgasova M, Aljabar P, Nunes RG, Larkman DJ, Rees G, Edwards AD (2010) Emergence of resting state networks in the preterm human brain. Proc Natl Acad Sci U S A 107:20015-20020. CrossRef Medline

Ellman LM, Deicken RF, Vinogradov S, Kremen WS, Poole JH, Kern DM, Tsai WY, Schaefer CA, Brown AS (2010) Structural brain alterations in schizophrenia following fetal exposure to the inflammatory cytokine interleukin-8. Schizophr Res 121:46-54. CrossRef Medline

Ernst GD, de Jonge LL, Hofman A, Lindemans J, Russcher H, Steegers EA, Jaddoe VW (2011) C-reactive protein levels in early pregnancy, fetal 
growth patterns, and the risk for neonatal complications: the Generation R Study. Am J Obstet Gynecol 205:132.e1-12. Medline

Estes ML, McAllister AK (2016) Maternal immune activation: implications for neuropsychiatric disorders. Science 353:772-777. CrossRef Medline

Fransson P, Aden U, Blennow M, Lagercrantz H (2011) The functional architecture of the infant brain as revealed by resting-state fMRI. Cereb Cortex 21:145-154. CrossRef Medline

Gabay C, Kushner I (1999) Acute-phase proteins and other systemic responses to inflammation. N Engl J Med 340:448-454. CrossRef Medline

Goeden N, Velasquez J, Arnold KA, Chan Y, Lund BT, Anderson GM, Bonnin A (2016) Maternal inflammation disrupts fetal neurodevelopment via increased placental output of serotonin to the fetal brain. J Neurosci 36:6041-6049. CrossRef Medline

Hunter CA, Jones SA (2015) IL-6 as a keystone cytokine in health and disease. Nat Immunol 16:448-457. CrossRef Medline

Jakab A, Schwartz E, Kasprian G, Gruber GM, Prayer D, Schöpf V, Langs G (2014) Fetal functional imaging portrays heterogeneous development of emerging human brain networks. Front Hum Neurosci 8:852. CrossRef Medline

Joshi A, Scheinost D, Okuda H, Belhachemi D, Murphy I, Staib LH, Papademetris X (2011) Unified framework for development, deployment and robust testing of neuroimaging algorithms. Neuroinformatics 9:6984. CrossRef Medline

Karlović D, Serretti A, Vrkić N, Martinac M, Marčinko D (2012) Serum concentrations of CRP, IL-6, TNF- $\alpha$ and cortisol in major depressive disorder with melancholic or atypical features. Psychiatry Res 198:74-80. CrossRef Medline

Lam C, Lim KH, Karumanchi SA (2005) Circulating angiogenic factors in the pathogenesis and prediction of preeclampsia. Hypertension 46:10771085. CrossRef Medline

Leviton A, Kuban K, Allred EN, Hecht JL, Onderdonk A, O'Shea TM, McElrath T, Paneth N; ELGAN Study Investigators (2010) Antenatal antecedents of a small head circumference at age 24 months post-term equivalent in a sample of infants born before the 28th post-menstrual week. Early Hum Dev 86:515-521. CrossRef Medline

Lo HC, Tsao LY, Hsu WY, Chen HN, Yu WK, Chi CY (2002) Relation of cord serum levels of growth hormone, insulin-like growth factors, insulin-like growth factor binding proteins, leptin, and interleukin- 6 with birth weight, birth length, and head circumference in term and preterm neonates. Nutrition 18:604-608. CrossRef Medline

Malkova NV, Yu CZ, Hsiao EY, Moore MJ, Patterson PH (2012) Maternal immune activation yields offspring displaying mouse versions of the three core symptoms of autism. Brain Behav Immun 26:607-616. CrossRef Medline

Mansur RB, Cunha GR, Asevedo E, Zugman A, Rizzo LB, Grassi-Oliveira R, Levandowski ML, Gadelha A, Pan PM, Teixeira AL, McIntyre RS, Mari JJ, Rohde LA, Miguel EC, Bressan RA, Brietzke E (2016) Association of serum interleukin-6 with mental health problems in children exposed to perinatal complications and social disadvantage. Psychoneuroendocrinology 71:94-101. CrossRef Medline

McEwen BS (2007) Physiology and neurobiology of stress and adaptation: central role of the brain. Physiol Rev 87:873-904. CrossRef Medline

Menon V (2011) Large-scale brain networks and psychopathology: a unifying triple network model. Trends Cogn Sci 15:483-506. CrossRef Medline

Meyer U, Murray PJ, Urwyler A, Yee BK, Schedlowski M, Feldon J (2008) Adult behavioral and pharmacological dysfunctions following disruption of the fetal brain balance between pro-inflammatory and IL-10mediated anti-inflammatory signaling. Mol Psychiatry 13:208-221. CrossRef Medline

Noble S, Spann MN, Tokoglu F, Shen X, Constable RT, Scheinost D (2017) Influences on the test-retest reliability of functional connectivity MRI and its relationship with behavioral utility. Cereb Cortex 27:5415-5429. CrossRef Medline

O'Neil A, Itsiopoulos C, Skouteris H, Opie RS, McPhie S, Hill B, Jacka FN (2014) Preventing mental health problems in offspring by targeting dietary intake of pregnant women. BMC Med 12:208. CrossRef Medline

Palaniyappan L, Liddle PF (2012) Does the salience network play a cardinal role in psychosis? An emerging hypothesis of insular dysfunction. J Psychiatry Neurosci 37:17-27. CrossRef Medline

Patterson PH (2002) Maternal infection: window on neuroimmune interactions in fetal brain development and mental illness. Curr Opin Neurobiol 12:115-118. CrossRef Medline
Patterson PH (2009) Immune involvement in schizophrenia and autism: etiology, pathology and animal models. Behav Brain Res 204:313-321. CrossRef Medline

Pepys MB, Hirschfield GM (2003) C-reactive protein: a critical update. J Clin Invest 111:1805-1812. CrossRef Medline

Peterson BS (2013) Editorial: from correlations to causation: the value of preventive interventions in studying pathogenic mechanisms in childhood psychiatric disorders. J Child Psychol Psychiatry 54:813-815. CrossRef Medline

Pipe JG (1999) Motion correction with PROPELLER MRI: application to head motion and free-breathing cardiac imaging. Magn Reson Med 42: 963-969. CrossRef Medline

Power JD, Cohen AL, Nelson SM, Wig GS, Barnes KA, Church JA, Vogel AC, Laumann TO, Miezin FM, Schlaggar BL, Petersen SE (2011) Functional network organization of the human brain. Neuron 72:665-678. CrossRef Medline

Scheinost D, Papademetris X, Constable RT (2014) The impact of image smoothness on intrinsic functional connectivity and head motion confounds. Neuroimage 95:13-21. CrossRef Medline

Scheinost D, Kwon SH, Shen X, Lacadie C, Schneider KC, Dai F, Ment LR, Constable RT (2016) Preterm birth alters neonatal, functional rich club organization. Brain Struct Funct 221:3211-3222. CrossRef Medline

Scheinost D, Sinha R, Cross SN, Kwon SH, Sze G, Constable RT, Ment LR (2017a) Does prenatal stress alter the developing connectome? Pediatr Res 81:214-226. CrossRef Medline

Scheinost D, Kwon SH, Lacadie C, Vohr BR, Schneider KC, Papademetris X, Constable RT, Ment LR (2017b) Alterations in anatomical covariance in the prematurely born. Cereb Cortex 27:534-543. CrossRef Medline

Seeley WW, Menon V, Schatzberg AF, Keller J, Glover GH, Kenna H, Reiss AL, Greicius MD (2007) Dissociable intrinsic connectivity networks for salience processing and executive control. J Neurosci 27:2349-2356. CrossRef Medline

Shanahan L, Bauldry S, Freeman J, Bondy CL (2014) Self-rated health and C-reactive protein in young adults. Brain Behav Immun 36:139-146. CrossRef Medline

Short SJ, Lubach GR, Karasin AI, Olsen CW, Styner M, Knickmeyer RC, Gilmore JH, Coe CL (2010) Maternal influenza infection during pregnancy impacts postnatal brain development in the rhesus monkey. Biol Psychiatry 67:965-973. CrossRef Medline

Sidlauskaite J, Sonuga-Barke E, Roeyers H, Wiersema JR (2016) Altered intrinsic organisation of brain networks implicated in attentional processes in adult attention-deficit/hyperactivity disorder: a resting-state study of attention, default mode and salience network connectivity. Eur Arch Psychiatry Clin Neurosci 266:349-357. CrossRef Medline

Smith L, Ulvund SE, Lindemann R (2001) Prediction of IQ among children with birth weight under 1,501 gms [Article in Norwegian]. Tidsskr Nor Laegeforen 121:1886-1891. Medline

Smith SE, Li J, Garbett K, Mirnics K, Patterson PH (2007) Maternal immune activation alters fetal brain development through interleukin-6. J Neurosci 27:10695-10702. CrossRef Medline

Smyser CD, Inder TE, Shimony JS, Hill JE, Degnan AJ, Snyder AZ, Neil JJ (2010) Longitudinal analysis of neural network development in preterm infants. Cereb Cortex 20:2852-2862. CrossRef Medline

Spann MN, Bansal R, Rosen TS, Peterson BS (2014) Morphological features of the neonatal brain support development of subsequent cognitive, language, and motor abilities. Hum Brain Mapp 35:4459-4474. CrossRef Medline

Spencer-Smith MM, Spittle AJ, Lee KJ, Doyle LW, Anderson PJ (2015) Bayley-III cognitive and language scales in preterm children. Pediatrics 135:e1258-e1265. CrossRef Medline

Stephan AH, Barres BA, Stevens B (2012) The complement system: an unexpected role in synaptic pruning during development and disease. Annu Rev Neurosci 35:369-389. CrossRef Medline

Tau GZ, Peterson BS (2010) Normal development of brain circuits. Neuropsychopharmacology 35:147-168. CrossRef Medline

Thomason ME, Scheinost D, Manning JH, Grove LE, Hect J, Marshall N, HernandezAndrade E, Berman S, Pappas A, Yeo L, Hassan SS, Constable RT, Ment LR, Romero R (2017) Weak functional connectivity in the human fetal brain prior to preterm birth. Sci Rep 7:39286. CrossRef Medline

Thompson BL, Levitt P, Stanwood GD (2009) Prenatal exposure to drugs: effects on brain development and implications for policy and education. Nat Rev Neurosci 10:303-312. CrossRef Medline 
Uddin LQ (2015) Salience processing and insular cortical function and dysfunction. Nat Rev Neurosci 16:55-61. CrossRef Medline

Uddin LQ, Supekar K, Lynch CJ, Khouzam A, Phillips J, Feinstein C, Ryali S, Menon V (2013) Salience network-based classification and prediction of symptom severity in children with autism. JAMA Psychiatry 70:869879. CrossRef Medline

Van Dijk KR, Sabuncu MR, Buckner RL (2012) The influence of head motion on intrinsic functional connectivity MRI. Neuroimage 59:431-438. CrossRef Medline

von Versen-Hoeynck FM, Hubel CA, Gallaher MJ, Gammill HS, Powers RW (2009) Plasma levels of inflammatory markers neopterin, sialic acid, and C-reactive protein in pregnancy and preeclampsia. Am J Hypertens 22: 687-692. CrossRef Medline

Wei H, Chadman KK, McCloskey DP, Sheikh AM, Malik M, Brown WT, Li X (2012) Brain IL-6 elevation causes neuronal circuitry imbalances and mediates autism-like behaviors. Biochim Biophys Acta 1822:831-842. CrossRef Medline

Wei H, Alberts I, Li X (2013) Brain IL-6 and autism. Neuroscience 252:320325. CrossRef Medline
Wium-Andersen MK, Ørsted DD, Nielsen SF, Nordestgaard BG (2013) Elevated C-reactive protein levels, psychological distress, and depression in 73, 131 individuals. JAMA Psychiatry 70:176-184. CrossRef Medline

Xing Z, Gauldie J, Cox G, Baumann H, Jordana M, Lei XF, Achong MK (1998) IL-6 is an antiinflammatory cytokine required for controlling local or systemic acute inflammatory responses. J Clin Invest 101:311-320. CrossRef Medline

Yasukawa H, Ohishi M, Mori H, Murakami M, Chinen T, Aki D, Hanada T, Takeda K, Akira S, Hoshijima M, Hirano T, Chien KR, Yoshimura A (2003) IL-6 induces an anti-inflammatory response in the absence of SOCS3 in macrophages. Nat Immunol 4:551-556. CrossRef Medline

Yeo BT, Krienen FM, Sepulcre J, Sabuncu MR, Lashkari D, Hollinshead M, Roffman JL, Smoller JW, Zöllei L, Polimeni JR, Fischl B, Liu H, Buckner RL (2011) The organization of the human cerebral cortex estimated by intrinsic functional connectivity. J Neurophysiol 106:1125-1165. CrossRef Medline

Zaretsky MV, Alexander JM, Byrd W, Bawdon RE (2004) Transfer of inflammatory cytokines across the placenta. Obstet Gynecol 103:546-550. CrossRef Medline 